\title{
Effect of Afghan Senjed (Elaeagnus Angustifolia L.) Leaves Aqueous Extract on Memory of Male Rats
}

\author{
Research Article
}

\section{Kawsar Alami', Mujtaba Haidari', Khalil Ebrahimi' ${ }^{1}$, Ali Ahmad Makarem Nasery Bakhtiari², Meysam Sajjadi', Sayed Yousof Mousavi ${ }^{*}$}

1. Research and Technology Center, Khatam Al-Nabieen University, Kabul, Afghanistan. 2. Medical Faculty, Khatam Al-Nabieen University, Kabul, Afghanistan.

3. Assistant Professor, Department of Physiology, Khatam Al-Nabieen University, Kabul, Afghanistan.

\begin{abstract}
This study is aimed to evaluate the effect of Elaeagnus Angustifolia leaves extract (EALE) on the memory of male rats. Rats were divided into 7 groups: 4 groups in the first stage (Control, EALE 100, 200 and $400 \mathrm{mg} / \mathrm{kg}$ ) to determine the effective-dose of EALE on memory; and 3 groups in the second stage (Normal, Scopolamine and EALE effective-dose) to evaluate the effect of EALE on scopolamine-induced memory impairment. Rats received EALE by i.p. administration for 14 days and the memory function of all groups was evaluated by the Y-maze test on days 8 and 15. Only scopolamine and effective dose of EALE groups were received scopolamine 30 min before Ymaze test. The total cholesterol and triglyceride levels of stage 2 rats were also measured. On day 8 , the percentage of spontaneous alternation (\%SA) was significantly increased in EALE $400 \mathrm{mg} / \mathrm{kg}$ group, as compared with the control group. On day 15, there was a significant difference in \%SA only between EALE $100 \mathrm{mg} / \mathrm{kg}$ group and the control group. The \%SA was significantly increased in the EALE effective-dose group only on day 15, as compared with scopolamine group $(\mathrm{P}<0.05)$. The effective-dose of EALE was also significantly decreased the total cholesterol $(\mathrm{P}<0.01)$ and triglyceride $(\mathrm{P}<0.001)$ levels in comparison with scopolamine group. In conclusion, a high dose of EALE only in a short-term administration period and its low dose in a long-term administration period had memoryenhancing effects. The low dose of EALE as an effective-dose of EALE could reverse the scopolamine-induced memory impairment.
\end{abstract}

Key Words: Afghanistan, Cholesterol, Elaeagnus Angustifolia, Leaves, Memory, Rat.

\section{Introduction}

Learning and memory are two fundamental abilities of human beings. Most of the knowledge about the world and the majority of the skills of humans are learned rather than innate. Thus, the behavior is greatly shaped on whatever one learns, memorizes and even forgets (1). Memory disorders can have effects on cognitive capabilities. There are a wide group of pathologies that may involve memory-related brain areas and thus impair the memory function (2). Alzheimer's disease is one of common neurodegenerative diseases, which characterized by progressive impairment of memory and cognition (3).

By increase of human population, the prevalence of Alzheimer's disease had increased (3). Despite the rapid progression of this disorder, scientists could not develop a highly ideal drug for this disease. Available synthetic drugs are relatively effective, but

* Corresponding Author:

Sayed Yousof Mousavi

Assistant Professor,

Department of Physiology,

Khatam Al-Nabieen University, $1^{\text {st }}$ street of Karte 4,

Kabul, Afghanistan.

Email Id: Mousavi.knurtc@knu.edu.af they have a long list of adverse side effects $(4,5)$. Fortunately, medicinal plants have fewer side effects and lower the rate of death and hospitalization $(5,6)$. For this reason, most researchers have a great interest in the use of medicinal plants to treat multiple diseases, including diabetes and Alzheimer's disease $(7,8)$.

Eleaegnus Angustifolia (E. Angustifolia), one of useful medicinal plants, is famous because of its therapeutic effects $(9,10)$. All parts of E. Angustifolia including leaves, flower, bark and fruit are known as their pharmacological and biological activities and have different effects (11). The leaves of E. Angustifolia have anti-microbial, anti-oxidative, anti-mutagenic activity (12), antidiabetic (13), and protective effects on the cardiovascular system (14).

E. Angustifolia leaves contain most useful constituents such as flavonoids, alkaloids, steroids, terpenoids, as well as beta-sitosterol (15). It has been shown that the amount of flavonoids in E. Angustifolia leaves is more than its flower (16).

Despite these useful properties and the presence of beneficial constituents in E. Angustifolia leaves, there is no evidence of any study on its memory-enhancing effect. This study is going to investigate the effect of aqueous extract of Afghan E. Angustifolia leaves on the memory of rats, using behavioral method. 


\section{Materials and Methods}

\section{Animals}

Fourthy-two adult wistar male rats weighing between 180 and $220 \mathrm{~g}$, randomly selected from Khatam Al-Nabieen University Research and Technology Center (KNURTC), were housed in Plexyglass cages with free access to food and water. Animals were kept under stable room temperature $\left(23 \pm 2^{\circ} \mathrm{C}\right)$ and a 12 hours light/dark cycle (the light period started at 7 a.m.). The experimental protocol related to animal's use has complied with all the relevant national regulations and institutional policies, so approved by the ethic research board of Khatam Al-Nabieen University and were conducted following the ethical guidelines set by the $8^{\text {th }}$ edition of National Institute of Health (NIH) guide for the care and use of laboratory animals. Rats were carefully handled to minimize unwanted stress during housing and experiments.

\section{Preparation of extract}

Fresh E. angustifolia leaves were collected from Kabul, Afghanistan. The leaves were washed in distilled water and dried in the shade. Thirty grams of leaves were grinded and extracted with $70^{\circ} \mathrm{C}$ distilled water thrice in an incubator at $85^{\circ} \mathrm{C}$ for $3 \mathrm{~h}$. Then, the water extract has filtered and concentrated in a vacuum rotary (Vargha Tajhiz, Iran) at $60^{\circ} \mathrm{C}$. Consequently, $E$. angustifolia leaves extract (EALE) was obtained (14).

\section{Experimental design}

This study was conducted in two stages:

\section{First stage}

In this stage, rats were randomly divided into 4 following groups $(n=6)$ to determine the effective-dose of EALE on memory:

Group I (Control), Rats of this group received Normal saline (1 ml, i.p.) for 14 days;

Group II-IV (EALE 100, 200, $400 \mathrm{mg} / \mathrm{kg}$ ), Rats of these groups received EALE (100, 200 and $400 \mathrm{mg} / \mathrm{kg}$, respectively, i.p.) for 14 days.

The memory function of rats was evaluated by the Ymaze test on days 8 and 15 .

\section{Second stage}

In this stage, rats were randomly divided into 3 following groups $(n=6)$ to evaluate the effect of EALE effective-dose on scopolamine-induced memory impairment:

Group I (Normal), Rats of this group received Normal saline (1 ml, i.p.) for 14 days, and $30 \mathrm{~min}$ before Ymaze test;

Group II (Scopolamine), Rats of this group received Normal saline (1 ml, i.p.) for 14 days, and Scopolamine hydrobromide (Sigma Aldrich, USA) $(2 \mathrm{mg} / \mathrm{kg}$, i.p.) 30 min before Y-maze test (17);

Group III (EALE effective dose), Rats of this group received EALE (100 mg/kg, i.p.) as effective-dose for 14 days, and Scopolamine hydrobromide $(2 \mathrm{mg} / \mathrm{kg}$, i.p.) 30 min before Y-maze test.

The memory function of all groups was evaluated by the Y-maze test on days 8 and 15. Also, after last behavioral test of the second stage groups, blood was withdrawn from their retroorbital plexus after mild anesthesia and postprandial serum total cholesterol and triglyceride levels were estimated by kits (Human, Germany).

\section{Y-maze}

A black plexy-glass maze $(50 \times 30 \times 11)$ constructed in research and technology center of Khatam Al-Nabieen (KNURTC), used in this study to evaluate the spatial working memory. A rat was placed in the Y-maze and allowed to move freely through the maze for $8 \mathrm{~min}$, without any rewards (e.g. food and water). If a rat entered three different arms consecutively, a spontaneous alternation (\%SA) was counted, as an index of spatial working memory. The number of entries into arms was considered as an index of locomotor activity $(18,19)$.

\section{Statistical analysis}

The statistical analysis was done with Graph pad prism (6.07) software. Parameters without considering the time were analyzed by One-way ANOVA test, and Two-way ANOVA analyzed the parameters with consideration of time. The difference amongst means was considered statistically significant if the $\mathrm{P}<0.05$. The results are expressed as mean $\pm \mathrm{SD}$.

\section{Results \\ Effect of EALE on \%SA}

On day 8 of the first stage, the $\% \mathrm{SA}$ was significantly $(\mathrm{P}<0.05)$ increased in EALE $400 \mathrm{mg} / \mathrm{kg}$ group (70.45 \pm 15.61$)$, but not in EALE 100 $(60.15 \pm 14.58)$ and $200 \mathrm{mg} / \mathrm{kg}(64.17 \pm 17.50)$ groups, as

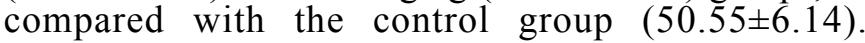
However, on day 15 of the first stage, \%SA was significantly $(\mathrm{P}<0.05)$ increased in EALE $100 \mathrm{mg} / \mathrm{kg}$ group $(72.05 \pm 9.41)$, but not in EALE 200 $(49.25 \pm 18.39)$ and $400 \mathrm{mg} / \mathrm{kg}(63.00 \pm 13.57)$ groups, as compared with the control group (49.08 \pm 9.48$)$ (Table 1, Figure 1). At the second stage, there was a significant difference between \%SA of normal and scopolamine groups on days 8 and $15(\mathrm{P}<0.05)$. However, there was a significant difference between $\% \mathrm{SA}$ of EALE effective dose $(67.43 \pm 9.06)$ and scopolamine $(50.52 \pm 14.37)$ groups only on day $15(\mathrm{P}<0.05)$ (Table 2, Figure 2).

\section{Effect of EALE on number of arm entries}

At the first stage, there was not a significant difference in the number of arm entries between each EALE 100, 200 and $400 \mathrm{mg} / \mathrm{kg}$ groups and the control groups on days 8 and $15(\mathrm{P}>0.05)$ (Table 1, Figure 3 ). Also, at the second stage, there was not a significant difference in the number of arm entries between each normal and EALE effective-dose groups and the scopolamine group on days 8 and $15(\mathrm{P}>0.05)$ (Table 2 , Figure 4).

\section{Effect of EALE on total cholesterol and Triglyceride}

There was a significant difference in total cholesterol level between normal and EALE effective dose and the scopolamine group $(\mathrm{P}<0.01)$. Also, there was a significant difference in Triglyceride level between normal and EALE effective dose and the scopolamine group $(\mathrm{P}<0.001)$ (Table 3$)$. 


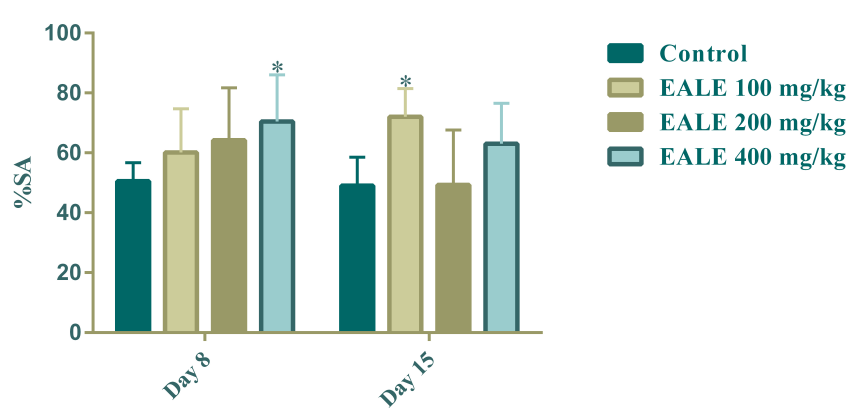

Figure 1. The effect of EALE on \%SA at the first stage. Data are shown as Mean \pm SD. ${ }^{*}: \mathrm{P}<0.05$ as compared with the control group. EALE, Eleaegnus angustifolia leaves extract; \%SA, Percentage of spontaneous alternation.

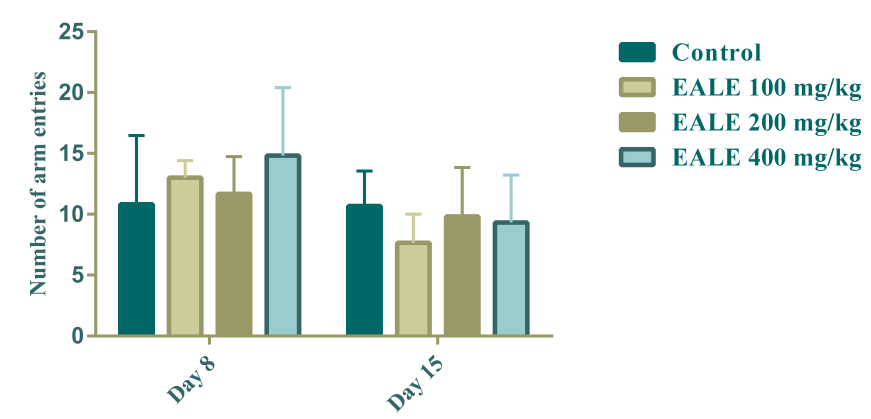

Figure 3. The effect of EALE on number of arm entries at the first stage. Data are shown as Mean \pm SD. EALE, Eleaegnus angustifolia leaves extract.

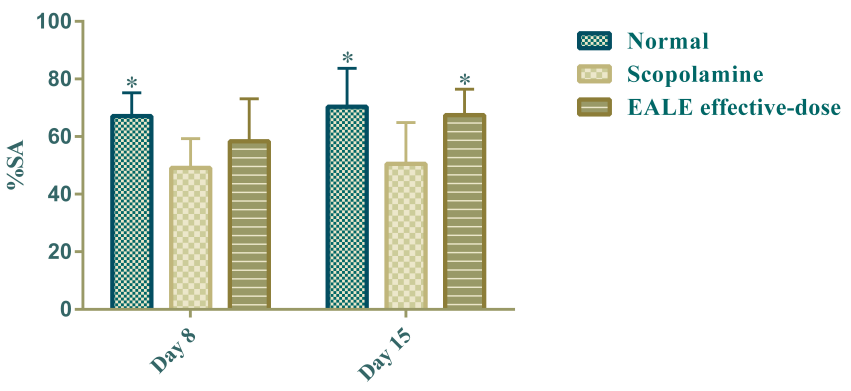

Figure 2. The effect of EALE on \%SA at the second stage. Data are shown as Mean \pm SD. ${ }^{*}: \mathrm{P}<0.05$ as compared with scopolamine group. EALE, Eleaegnus angustifolia leaves extract; \%SA, Percentage of spontaneous alternation.

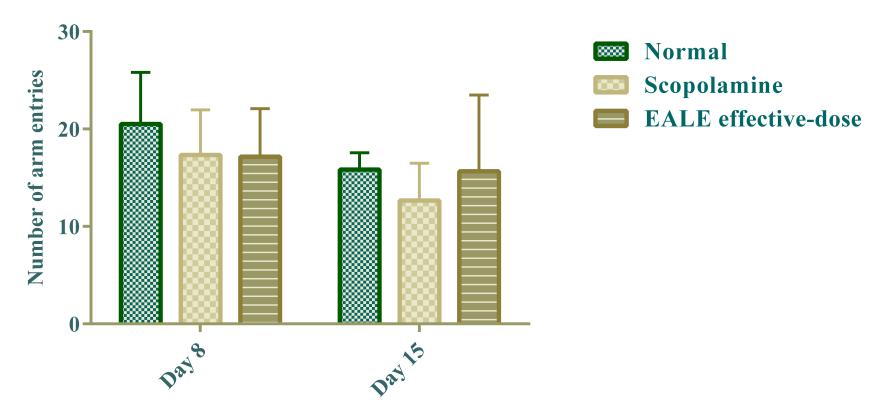

Figure 4. The effect of EALE on number of arm entries at the second stage. Data are shown as Mean \pm SD. EALE, Eleaegnus angustifolia leaves extract.

Table 1. The effect of EALE on \%SA and number of arm entries at the first stage

\begin{tabular}{|c|c|c|c|c|}
\hline \multirow{2}{*}{ Groups } & \multicolumn{2}{|c|}{$\% \mathrm{SA}$} & \multicolumn{2}{|c|}{ Number of arm entries } \\
\hline & Day 8 & Day 15 & Day 8 & Day 15 \\
\hline Control & $50.55 \pm 6.14$ & $49.08 \pm 9.48$ & $10.83 \pm 5.64$ & $10.67 \pm 2.87$ \\
\hline EALE 100 mg/kg & $60.15 \pm 14.58$ & $72.05 \pm 9.41 *$ & $13.00 \pm 1.41$ & $7.67 \pm 2.34$ \\
\hline EALE $200 \mathrm{mg} / \mathrm{kg}$ & $64.17 \pm 17.50$ & $49.25 \pm 18.39$ & $11.67 \pm 3.08$ & $9.83 \pm 4.02$ \\
\hline EALE $400 \mathrm{mg} / \mathrm{kg}$ & $70.45 \pm 15.61 *$ & $63.00 \pm 13.57$ & $14.83 \pm 5.56$ & $9.33 \pm 3.88$ \\
\hline Two-way ANOVA & $\begin{array}{l}F=5.361 \\
d f=3 \\
P=0.0071\end{array}$ & & $\begin{array}{l}F=0.3469 \\
d f=3 \\
P=0.7918\end{array}$ & \\
\hline
\end{tabular}

Data are shown as Mean \pm SD. ${ }^{*}: \mathrm{P}<0.05$ as compared with control group. EALE, Eleaegnus angustifolia leaves extract; \%SA, Percentage of spontaneous alternation; df, degree of freedom.

Table 2. The effect of EALE on \%SA and number of arm entries at the second stage

\begin{tabular}{|c|c|c|c|c|}
\hline \multirow{2}{*}{ Groups } & \multicolumn{2}{|c|}{$\% \mathrm{SA}$} & \multicolumn{2}{|c|}{ Number of arm entries } \\
\hline & Day 8 & Day 15 & Day 8 & Day 15 \\
\hline Normal & $67.14 \pm 8.10^{*}$ & $70.35 \pm 13.38 *$ & $20.50 \pm 5.32$ & $15.83 \pm 1.72$ \\
\hline Scopolamine & $49.16 \pm 10.11$ & $50.52 \pm 14.37$ & $17.33 \pm 4.63$ & $12.67 \pm 3.83$ \\
\hline EALE effective dose & $58.38 \pm 14.76$ & $67.43 \pm 9.06^{*}$ & $17.17 \pm 4.92$ & $15.67 \pm 7.81$ \\
\hline Two-way ANOVA & $\begin{array}{l}F=7.912 \\
d f=2 \\
P=0.0045\end{array}$ & & $\begin{array}{l}F=0.8692 \\
d f=2 \\
P=0.4394\end{array}$ & \\
\hline
\end{tabular}

Data are shown as Mean \pm SD. *: $\mathrm{P}<0.05$ as compared with scopolamine group. EALE, Eleaegnus angustifolia leaves extract; \%SA, Percentage of spontaneous alternation; df, degree of freedom. 
Table 3. The Effect of EALE on total cholesterol and triglyceride

\section{Normal Groups \\ Scopolamine \\ EALE effective-dose}

One-way ANOVA
Total cholesterol (mg/dl)

$99.76 \pm 5.60^{* *}$

$131.3 \pm 27.05$

$98.27 \pm 7.59^{* *}$
Triglyceride (mg/dl)

$105.1 \pm 11.21^{* * *}$

$166.2 \pm 11.87$

$\mathrm{F}=19.62$

$107.0 \pm 4.73^{* * *}$

$\mathrm{df}=2$

$\mathrm{P}=<0.0001$

Data are shown as Mean \pm SD. ${ }^{* *}: \mathrm{P}<0.01,{ }^{* * *}: \mathrm{P}<0.001$ as compared with the scopolamine group. EALE, Eleaegnus angustifolia leaves extract; $\mathrm{df}$, degree of freedom.

\section{Discussion}

In this study, the effect of EALE on the spatial working memory of male rats was evaluated. The results of the first stage experiments showed that the high-dose $(400 \mathrm{mg} / \mathrm{kg})$ of EALE increased the \%SA after short-term administration period (7 days). However, this high-dose of EALE could not increase the \%SA after long-term administration period (14 days). It means that the memory-enhancing effect of the high-dose of EALE is temporary, so it cannot improve the spatial working memory in long-term administration period. On the other hand, the low-dose $(100 \mathrm{mg} / \mathrm{kg})$ of EALE could not significantly increase the \%SA after short-term administration period. However, this lowdose of EALE significantly increased the \%SA after long-term administration period. It means that the lowdose of E. angustifolia leaves extract can improve spatial working memory in long-term administration period. Based on these results, we choose the $100 \mathrm{mg} /$ $\mathrm{kg}$ dose as EALE effective-dose and evaluated its effect on scopolamine-induced memory impairment.

Scopolamine is an anticholinergic drug, which produces reversible memory impairment in both rodents and humans. There are similarities in memory deficits between Alzheimer patients and scopolamine-treated rodents. Scopolamine is commonly used for evaluation of the antiamnestic property of herbs or drugs in rodents $(20,21)$.

Results of second stage experiments showed that the $\% \mathrm{SA}$ was significantly decreased in scopolamine group, as compared with a normal group in both days 8 and 15 . Thus, one can conclude that the administration of scopolamine in rats could develop memory impairment model. In addition, the EALE effective-dose could significantly increase the \%SA only after a long-administration period and reversed the scopolamine-induced memory impairment.

Besides, the number of arm entries was evaluated to exclude false-positive results. The experimental groups showed no significant differences regarding the number of entries into the arms, either after short-term or long-term administration period.

As there was not any study on the evaluation of the effect of EALE on memory, we cannot compare the results of this study with others.

Because the main constituents of E. angustifolia leaves are the flavonoid compounds and the betasitosterol terpene (22), this behavioral change may probably have resulted from the effect of these constituents on memory processes. Various studies have been shown that flavonoids may improve memory, by activation of neuronal receptors, signaling proteins and gene expression $(23,24)$. In a study that had been done on the effect of dietary flavonoids on the memory of young rats, suggested that flavonoids may induce changes in synapses and thus in the behavior, by various molecular mechanisms. Especially, the behavioral improvement is may related to an increase in the levels of polysialyted form of the neural adhesion molecule (PSA-NCAM) in the dentate gyrus of the hippocampus (23).

In addition, it is shown that scopolamine can increase acetylcholinesterase activity and reduce the acetylcholine level in the hippocampus, which leads to memory impairment. Therefore, many compounds with anti-acetylcholinesterase activity can reverse its effect and thus improve memory (21). There are reports that most of the plant-derived flavonoids possessed the antiacetylcholinesterase activity and showed antialzheimeric properties (25). In addition, the betasitosterol terpene, which is known as an antihypercholestrolemic compound, also showed antialzheimeric effects, due to its anti-acetylcholinesterase and antioxidant properties (26).

Despite these beneficial properties of the constituents of $E$. angustifolia leaves on memory, the present study showed that the high dose of EALE could not improve the memory during the long-term administration period. The ineffectiveness of high doses of EALE may have resulted from its sedative effects. There are some reports on sedative effects of $E$. angustifolia, which has been proposed that its flavonoid contents have a relative agonistic effect on benzodiazepine receptors and exerts sedative effect (10). Similarly, a previous study showed that low doses of Glycyrrhiza glabra can improve memory, but its high doses do not have a memory-enhancing effect, due to its sedative effects. Glycyrrhiza glabra also has flavonoid compounds (27).

Moreover, the administration of scopolamine in this study had increased the total cholesterol and triglyceride levels in rats and the EALE could decrease their levels significantly. There are multiple reports about the relation between high cholesterol level and Alzheimer's disease. Studies have been shown that hypercholesterolemia may increase the predisposition to Alzheimer's disease. The new therapeutic strategies are aimed at lowering blood cholesterol level is gathering momentum for the management of Alzheimer's disease (28). Hence, the memory-enhancing effect of EALE can 
be attributed to anti-acetylcholinesterase and also cholesterol-lowering activities of its constituents.

\section{Conclusion}

One can conclude that low dose $(100 \mathrm{mg} / \mathrm{kg})$ of Afghan EALE during a long-term administration period has memory-enhancing effect, reversed scopolamineinduced memory impairment in young rats and showed cholesterol-lowering properties. More studies seem to be needed to investigate the possible mechanisms responsible for the memory-enhancing property of this plant.

\section{Acknowledgements}

This work is supported by the research and technology center of Khatam Al-Nabieen University Kabul, Afghanistan. We thank all officials for their valuable support for providing the equipment and facilities for this study.

\section{References}

1. Kandel ER, Dudai Y, Mayford MR, The molecular and systems biology of memory. Cell. 2014; 157(1): 163-186. https://doi.org/10.1016/j.cell.2014.03.001

2. Matthews BR, Memory dysfunction. Continuum: Lifelong Learning in Neurology. Behavioral Neurology and Neuropsychiatry. 2015; 21(3): 613.

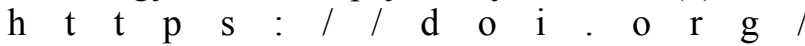
10.1212/01.CON.0000466656.59413.29

3. Lin R, Li L, Zhang Y, Huang S, Chen S, Shi J, Zhuo $\mathrm{P}$, Jin H, Li Z, Liu W, Wang Z, Electroacupuncture ameliorate learning and memory by improving $\mathrm{N}$-acetylaspartate and glutamate metabolism in APP/PS1 mice. Biol. Res. 2018; 51(1): 21. https:// doi.org/10.1186/s40659-018-0166-7

4. Pohanka M, Oxidative stress in alzheimer disease as a target for therapy. Bratisl. Med. J. 2018; 119(9): 535-543. https://doi.org/10.4149/BLL 2018 097

5. Karimi A, Majlesi M, Rafieian-Kopaei M, Herbal versus synthetic drugs; beliefs and facts. J. Nephropharmacol. 2015; 4(1): 27.

6. Akbari E, Alami K, Hossaini D, Nazari ML, Salehi MH, Sajjadi M, Mousavi SY, Effect of Afghan Saffron (Crocus sativus L.) aqueous extract on withdrawal signs in morphine-dependent rats. Pharmacog. J. 2020; 12(6s): 1727-1731. https:// doi.org/10.5530/pj.2020.12.234

7. Kazemipoor M, Radzi CW, Cordell GA, Yaze I, Safety, efficacy and metabolism of traditional medicinal plants in the management of obesity: a review. Int. J. Chem. Eng. Appl. 2012; 3(4): 288 292. https://doi.org/10.7763/IJCEA.2012.V3.201

8. Haidari M, Alami K, Hossaini A, Mousavi SY, Effect of Afghan Hibiscus sabdariffa L. and Carum Carvi L. Hydro-alcoholic Extracts Either Alone or in Combination on Blood Glucose Level in Diabetic Rats. Int J Ayurvedic Med. 2020; 11(4): 759-764. https://doi.org/10.47552/ijam.v11i4.1691

9. Natanzi MM, Pasalar P, Kamalinejad M, Dehpour AR, Tavangar SM, Sharifi R, Ghanadian N, Rahimi-Balaei M, Gerayesh-Nejad S, Effect of aqueous extract of Elaeagnus angustifolia fruit on experimental cutaneous wound healing in rats. Acta. Med. Iran. 2012; 50(9): 589-596.

10. Tehranizadeh ZA, Baratian A, Hosseinzadeh $\mathrm{H}$, Russian olive [Elaeagnus angustifolia] as a herbal healer. BioImpacts: BI. 2016; 6(3): 155. https:// doi.org/10.15171/bi.2016.22

11. Cheraghipoor M, Maghsoodlou MT, Faghihi MR, A Green, Novel and Efficient Protocol for the Preparation of Diverse 4 H-Pyrans: The First Report on the Catalytic Activity of Water Extract of Elaeagnus angustifolia Leaves in Organic Reactions. Polycycl. Aromat. Compd. 2019:1-10. https://doi.org/10.1080/10406638.2018.1557710

12. Okmen G, Turkcan O, A study on antimicrobial, antioxidant and antimutagenic activities of Elaeagnus angustifolia L. leaves. Afr. J. Tradit. Complement. Altern. Med. 2014; 11(1): 116-120. https://doi.org/10.4314/ajtcam.v11i1.17

13. Sadat H, Alami K, Mousavi SY, Effect of Afghan Senjed (Elaeagnus Angustifolia L.) Leaves Aqueous alcoholic Extract on Blood Glucose Level of Diabetic Rats. Pharmacogn J. 2020; 12(6): 1218-22. https://doi.org/10.5530/pj.2020.12.170

14. Wang B, Qu H, Ma J, Sun X, Wang D, Zheng Q, Xing D, Protective effects of Elaeagnus angustifolia leaf extract against myocardial ischemia/reperfusion injury in isolated rat heart. J. Chem. 2014; 2014. https://doi.org/10.1155/2014/693573

15. Azeez RA, Abaas IS, Kadhim EJ, Isolation and Characterization of $\beta$-sitosterol from Elaeagnus angustifolia cultivated in Iraq. Asian. J. Pharm. Clin. Res. 2018; 11(11): 442-426. https://doi.org/ 10.22159/ajpcr.2018.v11i11.29030

16. Saboonchian F, Jamei R, Sarghein SH, Phenolic and flavonoid content of Elaeagnus angustifolia L. (leaf and flower). Avicenna. J. Phytomed. 2014; 4(4): 231.

17. Cunha GM, Canas PM, Melo CS, Hockemeyer J, Müller CE, Oliveira CR, Cunha RA, Adenosine A $2 \mathrm{~A}$ receptor blockade prevents memory dysfunction caused by $\beta$-amyloid peptides but not by scopolamine or MK-801. Exp. Neurol. 2008; 210(2): 776-781. https://doi.org/10.1016/ j.expneurol.2007.11.013

18. Alami K, Mousavi SY, Afghan Chehelghoza (Pinus gerardiana L.) Pine Nut Diet Enhances the Learning and Memory in Male Rats. Nutr. Diet. Suppl. 2020; 12: 277-288. http://doi.org/10.2147/NDS.S278350

19. Kim JI, Jeon SG, Kim KA, Kim JJ, Song EJ, Jeon Y, Kim E, Lee KB, Kwak JH, Moon M, Platycodon grandiflorus Root Extract Improves Learning and Memory by Enhancing Synaptogenesis in Mice Hippocampus. Nutrients. 2017; 9(7): 794. https:// doi.org/10.3390/nu9070794

20. Seifhosseini S, Jahanshahi M, Moghimi A, Aazami NS, The effect of scopolamine on avoidance memory and hi2ppocampal neurons in male Wistar rats. Basic. Clin. Neurosci. 2011; 3(1): 9-15.

21. Harandi S, Golchin L, Ansari M, Moradi A, Shabani M, Sheibani V, Antiamnesic effects of walnuts consumption on scopolamine-induced memory 
Kawsar Alami et.al., Effect of Afghan Senjed (Elaeagnus Angustifolia L.) Leaves Aqueous Extract on Memory of Male Rats impairments in rats. Basic. Clin. Neurosci. 2015; 6(2): 91.

22. Ishaqat AA, Abu-Dahab R, Hammad HM, Al-Zihlif M, Abaza IF, Nassar ZD, Afifi FU, Phytochemical Analysis and Evaluation of Anti-angiogenic and Antiproliferative Activities of the Leaves of Elaeagnus angustifolia L. Grown in Jordan. Nat. Prod. Chem. Res. 2018; 6: 3. https://doi.org/ 10.4172/2329-6836.1000319

23. Rendeiro C, Foley A, Lau VC, Ring R, RodriguezMateos A, Vauzour D, Williams CM, Regan C, Spencer JP, A role for hippocampal PSA-NCAM and NMDA-NR2B receptor function in flavonoidinduced spatial memory improvements in young rats. Neuropharmacology. 2014; 79: 335-344. https://doi.org/10.1016/j.neuropharm.2013.12.003

24. Rendeiro C, Guerreiro JD, Williams CM, Spencer JP, Flavonoids as modulators of memory and learning: molecular interactions resulting in behavioural effects. Proc. Nutr. Soc. 2012; 71(2):
$246-262$. ht tps://doi.org/10.1017/ S0029665112000146

25. Khan H, Amin S, Kamal MA, Patel S, Flavonoids as acetylcholinesterase inhibitors: Current therapeutic standing and future prospects. Biomed. Pharmacother. 2018; 101: 860-870. https://doi.org/ 10.1016/j.biopha.2018.03.007

26. Ayaz M, Junaid M, Ullah F, Subhan F, Sadiq A, Ali G, Ovais M, Shahid M, Ahmad A, Wadood A, ElShazly M, Anti-Alzheimer's studies on $\beta$-sitosterol isolated from Polygonum hydropiper L. Front. Pharmacol. 2017; 8: 697. https://doi.org/10.3389/ fphar.2017.00697

27. Dhingra D, Parle M, Kulkarni SK, Memory enhancing activity of Glycyrrhiza glabra in mice. J. Ethnopharmacol. 2004; 91(2-3): 361-365. https:// doi.org/10.1016/j.jep.2004.01.016

28. Bansal N, Parle M, Soybean supplementation helps reverse age-and scopolamine-induced memory deficits in mice. J. Med. Food. 2010; 13(6): 1293-300. https://doi.org/10.1089/jmf.2010.1132. 